\title{
Cointegration Networks in Stock Markets
}

\author{
Vikkram Singh \\ Ph.D. Candidate at Griffith University \\ Email: vikkram.singh@griffithuni.edu.au
}

\author{
Dr. Eduardo Roca \\ Professor \\ Griffith Business School \\ Griffith University \\ Dr. Bin Li \\ Senior Lecturer \\ Griffith Business School \\ Griffith University
}

Corresponding author: Vikkram Singh, Department of Accounting, Finance and Economics, Griffith Business School, Griffith University, Queensland 4111, Australia; Email:

vikkram.singh@griffithuni.edu.au; Tel: +1-647-273-2892. 


\section{Cointegration Networks in Stock Markets}

\section{ABSTRACT}

We use a novel approach based on a combination of network and cointegration analysis to examine linkages between stock markets across market cycles. Our results show that long-run linkages are likely to be global rather than regional and that market turbulence increases linkages. However, we find no widespread common stochastic trends between markets and neither are we able to draw a conclusion that major financial markets display network linkages.

Keywords: cointegration network, equity markets, linkages, market turbulence. JEL Classification: F3, G1 


\section{Introduction}

We adopt a novel approach to analyse long-run linkages between markets using a network framework. This method allows us to capture the complexity of the relationships in evolving financial systems over time and across regions, which is hard to do using traditional methods such as correlation. The network analysis also enables us to use visualization techniques to detect complex interrelationship between markets. Very few studies (e.g., Hu, et al., 2013; Roy and Sarkar, 2011) apply network analysis to financial markets; however, to the best of our knowledge, the present study is the first one to estimate common stochastic trends or cointegration within a network framework. We test whether regional factors shape long-run network linkages and use network density to measure if traffic increases during times of crisis. Also, we explore the relationship between major financial markets (US, China, UK) and other markets to determine if the markets of global significance are likely to influence networks across market cycles.

Our research has important practical implications. First, the identification of long-run stochastic trends can help portfolio managers diversify their portfolios. Second, insights into the changes in linkages in market networks can assist policy makers to devise strategies to deal with a market crisis, especially those originating from across borders.

\section{Methodology}

We use the natural log prices of weekly stock market indices of the MSCI local currency country market index from the Thomson Reuters DataStream database from July 1997 to April 2015 as depicted in Table 1.

[Table 1 near here] 
By applying a combination of a network (Hu et al., 2013; Roy and Sarkar, 2011) and cointegration analysis (Engle and Granger, 2003), we can examine the long-run market linkages. The networks depict the links between the market pairs over the three regions. The nodes or the vertices in the network are the equity markets, and the edges display cointegration linkages. The results are visualized using both the weighted and the unweighted networks. The weighted networks are constructed using the cointegration coefficients of market pairs - the bigger the absolute values of the coefficients, the thicker the width of the edges. ${ }^{1}$ Furthermore, the density of the networks is calculated using a density score. The score ranges from 0 to 1 with a higher score indicating higher density, and is calculated as follows:

$$
D=E / N(N-1)
$$

where $E$ is the total number of actual linkages and $N$ is the total number of nodes. While the weighted networks identify the degree of long-run relationships in the network, the unweighted networks visualize the network traffic.

Although some studies such as Yang et al. (2014) and Chung and Liu (1994) measure cointegration between global markets, they suffer from a small sample bias especially when accounting for market crisis lasting for a short period. ${ }^{2}$ Our paper addresses this shortcoming by using a longer weekly data. We divide the data into two periods corresponding to the periods of calm and turbulence to observe the change in linkages during market distress. The ability to compare the relationships over the two periods is a useful addition to the current literature given that long-run relationships might break during times of market turbulence.

\footnotetext{
${ }^{1}$ Average coefficients are used to calculate weights in cases where two-way directed linkage exist between market pairs.

${ }^{2}$ Using Engle-Granger test for small sample periods in the presence of non-normality can be problematic (Siklos and Ng, 2001).
} 
The two sample periods used are:

- Period of turbulence: Early 2000 recession period (March 2001 to November 2001) plus the 2008 recession period (December 2007 to June 2009).

- Period of calm: Pre-2000 recession period (January 1997 to February 2001) plus the pre-2008 recession period (December 2001 to November 2007) and the post-2008 recession period (July 2009 to April 2015).

\section{Results}

The unweighted networks depict the regional linkages by dotted lines and the global linkages using solid lines, with the blue, orange and green nodes representing the markets in the Americas, Europe, and Asia-Pacific, respectively (Figures 1 and 2). Overall, only a small percentage of nodes report linkages - out of the 600 potential edges in each period, 77 edges form during the period of calm and 99 during the period of turbulence. Also, the number of global linkages exceed regional linkages in both periods as depicted by the higher traffic between regions compared to those within regions. Due to space limitations, we present the top 10 market pairs in both periods according to the strength of the cointegrating coefficients (Table 2). Several of the top equity pairs depict geographic proximity (DN-UK, SZ-UK, SWIT, ID-HK, ID-MY, ID-SG, IN-HK, KR-SG, IN-SG) mainly in Asia-Pacific and Europe.

The regional networks in Asia-Pacific report a density score higher than those in Europe and the Americas in both periods whereas the Americas display no local linkages (Table 3). We observe changes in networks between the two periods with the traffic increasing in AsiaPacific and Europe during the times of crisis. The increase in traffic in Europe is greater than that in Asia-Pacific which is likely due to the coordinated monetary and market intervention policies because of the existence of the EU in the region (Fratzscher, 2002). 
[Figure 1 here]

[Figure 2 here]

[Table 2 here]

[Table 3 here]

The colours blue, red and green depict the edges between the US, China and the UK and other markets, respectively, along with the degree of association depicted by the cointegration coefficients weights at $10 \%$ significance level (Figures 3a and 3b). Other than the UK, the other two markets do not exhibit strong linkages. The UK reports higher network traffic during both periods compared to the US and China, with most of the linkages being global. The UK reports strongest link with Germany during calm and Switzerland during the crisis period, both regional markets. Although the US displays no market linkages during times of calm, it reports five global linkages during the crisis period, with the strongest link being with the UK. The market turmoil originating from the US translates into higher linkages between the US and other markets predominately European during the period of turbulence. China reports no regional ties during the period of calm but displays linkages with Singapore and Korea during the times of turbulence. The strongest linkage reported by China is with Mexico and Norway during the period of calm and turbulence, respectively. Interestingly, these countries report strong trade relationships with China. ${ }^{3}$ Overall, the density scores depict an increase in network traffic during the period of turbulence $(0.17)$ compared to the period of calm (0.13). Furthermore, these linkages not only intensify, but they also grow with the addition of new nodes during the crisis period.

\footnotetext{
${ }^{3}$ Source: http://atlas.media.mit.edu/en/, retrieved on June 21, 2016.
} 
[Figures 3a here]

[Figures 3b here]

\section{Conclusion}

In this paper, we use network analysis with cointegration framework to examine how long-run linkages evolve between markets. Our results show that although market linkages are likely to be global rather than regional, the networks in Asia-Pacific report higher local density. Investigating the role of prominent financial centres, we find that even though the UK reports significant network traffic especially during times of crisis, the same is not true for the US and China. Thus, we are unable to conclude that prominent financial markets influence long-run global linkages. The influence of the UK in shaping regional long-run linkages may stem from the fact that it is a biggest and the most connected financial market in the EU. Finally, we find evidence that market turbulence increases market linkages due to the observed increase in the network density. Also, the long-run stochastic trends are likely to break during times of turbulence which may be attributable to the spread of market turmoil and volatility leading to negative sentiments across markets.

We find that despite increasing globalization of financial markets, long-run linkages are not widespread. The might be because the company-specific shocks evident in the stock prices inhibit cointegrating relationships, and the individual stochastic trends cancel out due to stock prices following a random walk (Dimpfl, 2014). The lack of broad long-run stochastic trends limits the opportunities for market participants to forecast prices of cointegrated markets using passive trading strategies. However, the few market pairs mainly global reporting common stochastic trend indicates isolated presence of frictions in the market networks and the time-varying market segmentation. These inefficiencies may be exploited 
using active global trading strategies, i.e. cointegration vectors can be used to estimate portfolio weights to optimize portfolios. Our results also provide insights into the dynamic nature of networks, which can assist policy makers in devising policies to deal with a market crisis, especially those coming from unrelated markets. 


\section{Disclosure Statement}

No potential conflict of interest was reported by the authors. 


\section{References}

Chung, P.J. and D. J. Liu. 1994. "Common stochastic trends in Pacific Rim stock markets.” Quarterly Review of Economics 34: 241-259.

Dimpfl, T. 2014. “A note on cointegration of international stock market indices." International Review of Financial Analysis 33: 10-16.

Engle, R., and C. Granger. 2003. "Time-series econometrics: cointegration and autoregressive conditional heteroskedasticity." Advanced information on the Bank of Sweden Prize in Economic Sciences in Memory of Alfred Nobel, 1-30.

Fratzscher, M. (2002), "Financial Market Integration in Europe: On the Effects of EMU on Stock Markets,” International Journal of Finance and Economics 7: 165-193.

Hu, S., H. Yang, B. Cai, and C. Yang. 2013. "Research on spatial economic structure for different economic sectors from a perspective of a complex network." Physica A: Statistical Mechanics and its Applications 392: 3682-3697.

MacKinnon, J. G., 2010. “Critical Values for Co-Integration Tests.” Queen's Economics Department Working Paper 1227.

Roy, R. B., and U. K. Sarkar. 2011. "Identifying influential stock indices from global stock markets: A social network analysis approach,” Procedia Computer Science 5: 442-449.

Siklos, P. L., and P. Ng. 2001. "Integration Among Asia-Pacific and International Stock Markets: Common Stochastic Trends and Regime Shifts.” Pacific Economic Review 6: 89-110.

Yang, C., Y. Chen, L. Niu, and Q. Li. 2014. "Cointegration analysis and influence rank-A network approach to global stock markets.” Physica A: Statistical Mechanics and its Applications 400: 168-185. 
Table 1: Markets

AMERICAS Argentina(AR), Brazil(BR), Canada(CA), Mexico(MX), United States of America(US)

ASIA- Australia(AU), China(CN), Hong Kong(HK), India(IN), Japan(JP), New

PACIFIC Zealand(NZ), Singapore(SG), Indonesia(ID), Malaysia (MY), South Korea(KR)

EUROPE $\quad$ Denmark(DN), France(FN), Germany(GM), Greece(GR), Italy(IT), Norway(NO), Russia(RU), Switzerland(SZ), Sweden(SW), United Kingdom(UK) 
Table 2: Top 10 linkages

\begin{tabular}{|c|c|c|c|}
\hline \multicolumn{4}{|c|}{ Period of Calm } \\
\hline & Market-Pairs & Coefficient & $t$-test \\
\hline 1 & SZ-HK & 2.9579 & $-3.21^{*}$ \\
\hline 2 & SW-IT & 2.6386 & $-3.75^{* *}$ \\
\hline 3 & ID-HK & 2.6224 & $-3.26 *$ \\
\hline 4 & IN-CA & 2.2543 & $-3.07 *$ \\
\hline 5 & ID-MY & 2.1880 & $-3.39 * *$ \\
\hline 6 & MY-DN & 2.1880 & $-3.45^{* *}$ \\
\hline 7 & MX-HK & 2.1380 & $-3.75^{* *}$ \\
\hline 8 & BR-SG & 2.1140 & $-3.26 *$ \\
\hline 9 & IN-HK & 2.1129 & $-3.80 * *$ \\
\hline 10 & KR-SG & 1.8438 & $-3.18 *$ \\
\hline \multicolumn{4}{|c|}{ Period of Turbulence } \\
\hline 1 & SZ-SG & 3.7155 & $-4.65 * * *$ \\
\hline 2 & ID-SG & 3.7079 & $-4.86 * * *$ \\
\hline 3 & ID-HK & 3.3720 & $-3.42 * *$ \\
\hline 4 & ID-UK & 3.3720 & $-3.10^{*}$ \\
\hline 5 & ID-NO & 3.3456 & $-3.39 * *$ \\
\hline 6 & DN-UK & 3.0203 & $-3.17 *$ \\
\hline 7 & IN-CA & 2.8161 & $-3.30 *$ \\
\hline 8 & SZ-UK & 2.8016 & $-3.07 *$ \\
\hline 9 & SZ-HK & 2.8016 & $-3.56^{* *}$ \\
\hline 10 & IN-SG & 2.7563 & $-3.51 * *$ \\
\hline
\end{tabular}


Table 3: Density Network

\begin{tabular}{lcc}
\hline & Period of Calm & Period of Turbulence \\
\hline Full network & 0.13 & 0.17 \\
\hline Asia-Pacific & 0.20 & 0.30 \\
\hline Europe & 0.07 & 0.16 \\
\hline Americas & 0.00 & 0.00 \\
\hline
\end{tabular}

